\title{
Plagiarism Instruction Online: Assessing Undergraduate Students' Ability to Avoid Plagiarism
}

\author{
Pamela A. Jackson
}

This study assesses undergraduate students' understanding of plagiarism through the use of an interactive, Web-based tutorial, Plagiarism: The Crime of Intellectual Kidnapping. The author details the instructional design process used to create this information literacy resource and integrate it into the curriculum. Data from 2,829 student quiz scores are analyzed to assess student learning. The results of this study indicate that students have difficulty grasping concepts related to paraphrasing. A comparative analysis of pre- and posttest results shows that student scores improved an average of 6 percent.

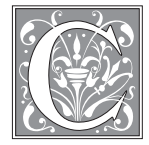

ampuses nationwide are increasingly aware of plagiarism problems in academic communities. Studies conducted by the Center for Academic Integrity point to an increase in plagiarism, with over 75 percent of students admitting to some cheating. ${ }^{1}$ High profile cases of plagiarism in journalism, politics, and other professional fields have brought more media attention to widespread plagiarism problems from high school students to career professionals. ${ }^{2}$ On a 2004 episode of Primetime Thursday, students told host Charles Gibson that competition for good grades, coupled with the lack of enforcement against cheating, make academic integrity seem unimportant. ${ }^{3}$ Many college campuses are pushing for higher levels of academic integrity through the creation of new policies and awareness programs.
Educators are calling for strengthened teaching methodologies to help students avoid plagiarism. To answer the call, librarians are looking for pedagogical ways to help campuswide initiatives in support of a culture of integrity.

To have the most effective impact, plagiarism instruction should be infused throughout students' everyday academic lives. Librarians continually work with instructors to develop plagiarism-proof assignments and tailor discipline-specific instruction. As will be explored in the literature review, research shows that students lack a fundamental understanding of what constitutes plagiarism and how to avoid it. The library, as a center for teaching and learning, is in a unique position to provide wide-scale plagiarism instruction through the use of Web-based information literacy tutorials, such as Plagiarism:

Pamela A. Jackson is Information Literacy Librarian at San Diego State University; e-mail: pjackson@rohan. sdsu.edu. Special thanks to the tutorial development team: Bridget Kowalczyk, Information Literacy Competency Coordinator; Jie (Jessie) Cai, programming; Wan Si Wan, graphics and animation; Andrea Lam, graphics; Baotran (Jenny) La, programming; and the King Library Web Team, testing and technical support. 
The Crime of Intellectual Kidnapping ${ }^{4}$ at San José State University (SJSU).

Libraries recognize the need for innovative ways to stimulate student learning in a digital age in which students' educational expectations revolve around technology. ${ }^{5}$ Web-based information literacy tutorials allow students to learn important research skills at their own pace, outside traditional class time and classrooms. Web-based instruction affords students the opportunity to learn when it is convenient for them. Online tutorials may be suited to individual learning styles as they employ text, audio, visual, and hands-on application of knowledge. Web-based tutorials are one successful way to provide a common foundation of knowledge among students, allowing librarians to make the most of their physical time with students in the classroom during what is usually a one-hour, one-shot library instruction session. Studies show that Web-based tutorials are at least as effective as in-person library instruction in teaching students information literacy skills. ${ }^{6}$

This article first details the instructional design process used to create and integrate this Web-based tutorial into the curriculum. The research study investigates students' understanding of plagiarism, paraphrasing, and citing sources. The major goals of this study were to assess whether or not the tutorial improved students' understanding of plagiarism; ascertain which academic colleges or programs are integrating the tutorial into their curriculum; and identify areas in which students need more instruction related to plagiarism and academic integrity. Based on conversations with instructors and a review of the literature, the working hypothesis for this study was that students' posttest scores would be higher than their pretest scores but that they would show difficulty grasping concepts related to paraphrasing.

\section{Review of the Literature Library's Role in Plagiarism Instruction} Much has been written about policing and detecting plagiarism. ${ }^{7}$ In recent years, more has been written to encourage librarians, as educators and collaborators, to take on more active roles in plagiarism instruction. Both John Gresham and Margaret Burke advocate for librarians raising awareness of plagiarism and detection services. However, Burke concludes that educating students about plagiarism and how to avoid it should be the primary concentration in universities. ${ }^{8}$

As a center for learning on campus, it makes sense that libraries be involved in plagiarism awareness and instruction. D. Scott Brandt notes that librarians are in a unique position to understand plagiarism in its broader context and proposes five ways for librarians to get involved, including defining plagiarism for students and using examples that place plagiarism in context. ${ }^{9}$ In their article about the library's role in plagiarism instruction, Nicole J. Auer and Ellen M. Krupar suggest that librarians proactively seek new opportunities to discuss the ethical use of information with students. ${ }^{10}$

Aside from including plagiarism instruction in what is usually a one-hour, one-shot library instruction session, librarians are encouraged to collaborate with instructors on assignments that prevent plagiarism and promote information literacy. Auer and Krupar suggest that "Librarians, as research and information literacy experts, should help faculty examine their existing or future assignments to determine the ease with which students could plagiarize." ${ }^{11}$ Janet McNeil Hurlbert, Cathleen R. Savidge, and Georgia L. Laudenslager emphasize the need for librarians to work with instructors on creating learner-centered, process-based research assignments that focus on the information sources used and require students to develop higher-level critical thinking and evaluation skills. ${ }^{12}$ Lynn D. Lampert points out that while information about plagiarism detection is important, librarians and instructors should collaborate to develop discipline-specific plagiarism instruction to make academic integrity more meaningful to students. ${ }^{13}$ 


\section{Students Lack Understanding of Plagia- rism and Proper Paraphrasing}

Research on academic integrity provides valuable insight into students' understanding of plagiarism. Brandt raises the question, "Can it be possible that students today don't really understand what plagiarism is?"14 There is clearly evidence to support the notion that students, in fact, do not understand plagiarism and lack the necessary skills to avoid it.

In 1994, Stephen Wilhoit suggested that educators spend more time teaching students how to avoid plagiarism. He notes that while some students make a conscious decision to cheat, there are many incidents of accidental plagiarism. ${ }^{15}$ Many authors agree that students lack understanding of what constitutes plagiarism, how to properly paraphrase, what needs to be cited, and how to cite sources. ${ }^{16}$ In their 1996 article, Donald McCabe and Linda Klebe Trevino show that while plagiarism rates have gone down slightly over time, failing to properly cite a source has gone up. ${ }^{17}$ Ruth Stubbings and Alan Brine's survey of undergraduate students at Loughborough University concludes that students are aware of the need for citation but are unsure of how to document sources. Furthermore, only 54 percent of the students they studied agreed or strongly agreed that rewording a passage without citing the original source is plagiarism. ${ }^{18}$

Recent plagiarism research strongly concludes that students lack an understanding of and ability to paraphrase. In 1997, Miguel Roig tested students' ability to recognize plagiarized text by giving students original and paraphrased passages. Roig notes that students "appeared to be confused as to the extent to which original text needs to be modified and about the conditions under which a citation is necessary." ${ }^{19}$ In 1999, Roig conducted a second study that asked students to read an original passage and write a paraphrase. When the original passage was more complex, either in subject matter or reading level, students were more likely to plagiarize by simply rearranging the passage, leaving more of the author's original language in their paraphrase. ${ }^{20}$ A significant relationship between plagiarism and students' knowledge of citing sources and proper paraphrasing is evident. In 2004, Julio G. Soto, Sulekha Anand, and Elizabeth McGee studied three biology courses to determine which anti-plagiarism instructional methods work best and concluded: "All students who plagiarized had problems with proper paraphrasing" 21

It is not only clear that students lack the ability to paraphrase, but they also have a hierarchical view of academic integrity. In 1997, Peter Ashworth, Philip Bannister, and Pauline Thorne interviewed students to better understand plagiarism from the students' point of view. Their study shows that while students perceive a clear line between cheating and plagiarism, the latter is viewed as a lesser offense to academic integrity. ${ }^{22}$ Verity J. Brown and Mark E. Howell's 2001 study found that students view paraphrasing without attributing the source a lesser offense than quoting directly from a source without proper citation. In fact, they found that only half of the respondents thought it "absolutely necessary" to cite paraphrased passages. ${ }^{23}$ Studies such as these may indicate that students' understanding of intellectual property is based on the actual words but not ideas of another author.

Some authors argue that writing methods typically considered plagiarism, such as piecing together sentences from original passages, are a necessary step for students to learn how to write and engage with scholarly literature. ${ }^{24}$ Nevertheless, most scholars agree on the importance of academic integrity and teaching students to avoid plagiarism. McCabe and Trevino stress that: “...creating a culture of academic integrity takes years to achieve and demands the commitment of all members of the campus community." ${ }^{25}$ Thus, the process 
by which librarians involve themselves in academic integrity instruction takes diligent planning. There is no single strategy for librarians and instructors to deter or eliminate plagiarism; however, as C. Brian Smith keenly points out, it is important for librarians to collaborate with campus instructors and administrators to create an overall culture of integrity that deters plagiarism. ${ }^{26}$

\section{Background}

In spring 2003, SJSU computer science instructors asked the author, formerly the computer science librarian at SJSU, to help instruct their students about plagiarism. Instructors Debra Caires-Mullens and June Sheldon stated: "Last spring [2003], in order to address the issue of plagiarism, we submitted course assignments to turnitin. com and were astounded to discover that between sixty-three to seventy-five percent of our students plagiarized." ${ }^{27}$ Plagiarism detection services, such as Turnitin.com, Eve2, and Glatt Plagiarism Services use specialized technology to compare student papers with information found on the Internet as well as databases of previously submitted papers and provide instructors with reports suggesting how much of a paper is original work and how much, if any, is plagiarized. ${ }^{28}$ Approximately 150 students complete this required upperdivision technical writing course every semester. Each semester, the librarian taught a 75-minute information literacy instruction session during regular class time. For many students, finding, evaluating, and incorporating advanced scientific research articles into their scholarly work is new. ${ }^{29}$ The librarian sought an innovative pedagogical approach to include plagiarism instruction without adversely affecting time for other important information literacy concepts critical to students' academic success in the course.

\section{Instructional Design: Assessing Curricular Needs}

Computer science technical writing instructors and the librarian collabo- rated on an instructional plan to teach computer science majors more about plagiarism, paraphrasing, and citing sources. The instructors and librarian wanted students to have a basic understanding of what constitutes plagiarism, what types of information need to be cited, and how to paraphrase. Concern about accidental plagiarism took precedent over the concern of students consciously cheating. This collaboration resulted in the creation of an interactive, Web-based information literacy tutorial about plagiarism. Although initially created for computer science students, the tutorial quickly gained popularity at all academic levels and in various departments campuswide.

\section{Designing the Tutorial}

Plagiarism: The Crime of Intellectual Kidnapping $^{30}$ teaches the basics of plagiarism, paraphrasing, and citing sources. Included are definitions of plagiarism with examples, links to detailed information about SJSU's Academic Integrity Policy, and an introduction to plagiarism detection services. Students are introduced to various citation styles and given examples of how to convert database and catalog citations into the two most commonly used styles on campus, MLA and APA.

The most beneficial aspect of the tutorial is its paraphrasing examples. Students are asked to read original and paraphrased passages to determine if plagiarism has occurred. To engage students from various academic disciplines, the passages draw on examples from the humanities, social sciences, and sciences. The instructional portion of the tutorial explains whether or not the paraphrase is plagiarized and why.

\section{Development Team}

A six-person team within the San José State University Academic Services Department of the Dr. Martin Luther King, Jr. Library developed the tutorial. In consultation with computer science 
technical writing instructors, the team's librarian, with a master's degree in English and rhetoric and writing teaching experience herself, crafted the tutorial content and wrote the pre- and posttests. The department's Information Literacy Competency Coordinator oversaw the programming and graphics team. Two student programmers pursuing master's degrees in Software Engineering and Computer Science were responsible for HTML, PHP, SQL, Javascript, and backend quiz databases and queries. Two student graphic artists pursuing bachelor's degrees in Fine Arts with emphases in Graphic Design and Animation/Illustration were responsible for the artwork, Macromedia Flash animations, and overall look of the tutorial using Adobe Photoshop CS and Illustrator.

\section{Timeline and Technology}

In spring 2003, the author surveyed available online plagiarism resources and found that, while there were many valuable text-based Web sites that tackled the topic of plagiarism, interactive digital learning resources that measure student learning were almost nonexistent. The author found one Web site that included an interactive true/false self-assessment quiz about plagiarism. ${ }^{31}$ However, an original pretest was written to match student learning outcomes to the instruction and to enable comparison of students' pre- and posttest scores.

Programmers transferred the basic HTML tutorial into PHP-enabled Web pages and created the registration page and back-end quiz database using MySQL. Meanwhile, the graphic artists began illustrating, creating an icon, and giving the tutorial its overall aesthetic look. After testing the tutorial in various Web browsers and versions for technological glitches and ADA compliance, the tutorial was launched in fall 2003.

An animated Flash version of the tutorial, launched in summer 2004, helped capture the students' attention and reinforced important tutorial concepts.
Students chose to complete the animated version or non-Flash version depending on their preferred learning style, disabilities requirements, and technical constraints such as processor and Internet connectivity bandwidth speeds.

\section{Open Publication License}

In response to the growing number of requests from other institutions, SJSU made the tutorial available for download and adaptation via an Open Publication License in fall 2004. To help set a standard for Web-based information literacy resource sharing, the Open Publication License is based on those of other libraries, such as TILT and UC Santa Cruz's NetTrail. ${ }^{32}$ While creating a file for download may seem like a relatively easy process, there are many factors to be considered, such as which files and formats to make available, how to collect and record data on who downloads the tutorial, and writing a technical instruction manual for other institutions to successfully adapt and use the tutorial.

\section{Integrating the Tutorial into the Curriculum}

Librarians continually work to infuse information literacy into campuswide curricula. The fact that Web-based information literacy tutorials assess student learning and enhance instruction without taking time away from instructors' or librarians' in-person class time is an important point to consider when asking educators to incorporate the tutorial into their departmental curriculum or individual courses.

The tutorial is a mandatory requirement for all computer science majors enrolled in the technical writing course-a course required for graduation. While initially created to address the needs of computer science majors, the tutorial quickly gained popularity among instructors in various departments and has been integrated into numerous courses across the curriculum. Additionally, in fall 2004, the library began working with first-time 
freshman Metropolitan University Scholars Experience (M.U.S.E.) instructors campuswide to include this tutorial, among other library tutorials, as a mandatory class assignment.

\section{Assessment of Student Learning: Quizzes and Queries}

The tutorial includes a pretest, assessing what students already know, and a graded quiz at the end, testing students' understanding of plagiarism and their ability to avoid it. Students registered to take the tutorial, and quiz scores were automatically e-mailed to them upon completion. Basic demographic data such as name, class level, and course for which they were taking the tutorial was collected. Assessment results were stored in a local MySQL database located on the library's Apache server.

Quiz questions assessed students' basic understanding of plagiarism, penalties if caught, and what needs to be cited. More important, the quiz assessed students' ability to recognize and avoid plagiarism in paraphrases. Students were given an original passage and a paraphrase. They decided what, if anything, was wrong with the paraphrase. As will become apparent in the analysis of quiz data, students had the most difficulty with paraphrasing questions. To help students gain even more paraphrasing experience, they were given an original passage and asked to para- phrase it themselves. Credit was given for attempting an answer. Although the computer cannot actually grade the paraphrases, answers provided instructors with data for teachable moments to help build on the instructional needs of an individual class.

The original multiple-choice question quiz lacked adherence to strong testwriting standards. Most librarians have not had much training in instructional design or student assessment methods such as writing tests. Librarians developing multiple-choice assessment tools should carefully consider the research on test development and seek out the support of campus units, such as centers for teaching and learning, faculty development, or testing offices. Tips for writing strong multiple-choice questions include: writing the stem in the form of a complete statement or question with enough information, ensuring that distracters (wrong answers) are clearly incorrect but not glib or too easy, and limiting the use of negatives unless absolutely necessary. ${ }^{33}$ Table 1 lists a representative sample of how the old test questions were rewritten to adhere to stronger multiple-choice test-writing standards.

Protecting the integrity of student assessment in the online environment is a growing concern. To reduce students' ability to share answers as the tutorial is integrated into the campuswide cur-

\begin{tabular}{|l|l|}
\hline \multicolumn{2}{|c|}{ TABLE 1 } \\
Comparison of Old and New Multiple-Choice Test Questions \\
\hline \hline Old Question & New Question \\
\hline You do NOT need to cite: & Which of the following needs to be cited? \\
\hline $\begin{array}{l}\text { It is acceptable to copy various forms of } \\
\text { multimedia, such as charts, graphs, photo- } \\
\text { graphs, videos, audio files if: }\end{array}$ & $\begin{array}{l}\text { When is it acceptable to use multimedia, } \\
\text { such as charts, graphs, photographs, videos, } \\
\text { or audio files in your paper or class presen- } \\
\text { tation? }\end{array}$ \\
\hline Acceptable paraphrasing is: & $\begin{array}{l}\text { Which of the following best describes ac- } \\
\text { ceptable paraphrasing? }\end{array}$ \\
\hline Direct quotes and paraphrases are used best: & $\begin{array}{l}\text { Which of the following is the best reason to } \\
\text { use direct quotes and paraphrases? }\end{array}$ \\
\hline
\end{tabular}




\begin{tabular}{|l|c|c|}
\hline \multicolumn{3}{|c|}{ TABLE 2 } \\
\multicolumn{2}{|c|}{$\begin{array}{c}\text { Number of Students and Mean Post- } \\
\text { test Score by Level (N = 2,829) }\end{array}$} \\
\hline \hline Student Level & $\begin{array}{c}\text { No. of } \\
\text { Students }\end{array}$ & $\begin{array}{c}\text { Mean } \\
\text { Score \% }\end{array}$ \\
\hline Upper division & 964 & 81.6 \\
\hline Lower division & 467 & 80.9 \\
\hline First-time freshman & 178 & 79.5 \\
\hline Other, not identified & 1,220 & 81.5 \\
\hline
\end{tabular}

scores are not included from the very small handful of graduate students who completed the tutorial.

Most students completed the tutorial as part of a class assignment. Of the 2,829 students included in this study, 964 were registered in upper-division courses, 467 in lower-division courses, 178 in first-time freshman seminars, and 1,220 either did not identify or were not registered as part of a course. Three hundred and forty-four students riculum, the tutorial team is working on a database of rotating quiz questions that will, at a minimum, triple the number of quiz questions available in a pool. The database will randomly select questions, ensuring that each student receives a slightly different quiz.

Query reports displayed quiz data by course, individual student, and semester. They included overall scores, class average scores per question, and students' answers per question. Query reports were shared with instructors to give insight into their students' understanding of academic integrity and to ease the burden of grading. The most important benefit of query reports was their ability to influence change in classroom instruction. Both librarians and instructors were able to view a specific course's tutorial scores to determine which concepts students understood and which may need further explanation and instruction to reinforce student learning and retention of information.

\section{Analysis of Student Quiz Results}

During the 2004-2005 academic year (August of 2004 to May of 2005), 3,224 individuals registered for the tutorial. Data from 2,829 students is included in this analysis. A total of 395 scores were not included in this study for the following reasons: individual registered just to test the system, student registered but did not record a score (often happens when students drop a course before completing the tutorial), or student did not complete both the pre- and posttests. Additionally, completed the tutorial for a course in the Applied Arts \& Sciences, 217 in Arts \& Humanities, 59 in Business, 212 in Education, 6 in Engineering, 408 in Sciences, 363 in Social Sciences, and 1,220 either did not identify or were not registered as part of a course. It is interesting to note that few students registered for the tutorial in conjunction with Business courses, and even fewer students registered in conjunction with Engineering courses. Librarians' commitment to outreach and instructors' willingness to include this information literacy resource as part of their plagiarism instruction may help reach a more diverse group of students.

The average overall posttest score, including paraphrasing portions, was 80.9 percent. A slight difference can be

\begin{tabular}{|l|c|}
\hline \multicolumn{2}{|c|}{$\begin{array}{c}\text { TABLE 3 } \\
\text { Number of Students by College } \\
(\mathbf{N}=\mathbf{2 , 8 2 9 )}\end{array}$} \\
\hline \hline College & $\begin{array}{c}\text { No. of } \\
\text { Students }\end{array}$ \\
\hline Applied Arts \& Sciences & 344 \\
\hline Arts \& Humanities & 217 \\
\hline Business & 59 \\
\hline Education & 212 \\
\hline Engineering & 6 \\
\hline Science & 308 \\
\hline Social Science & 1,220 \\
\hline Other, unidentified & \\
\hline $\begin{array}{l}\text { Note: College may not correlate to } \\
\text { students' major. }\end{array}$ \\
\hline
\end{tabular}


seen between student levels. The average posttest scores by level were 81.6 percent for students registered in upper-division courses, 80.9 percent for lower-division, 79.5 percent for first-time freshmen, and 81.5 percent for other students not associated with a course (see table 2). While more research is needed, initial study suggests that incoming freshmen have an understanding of plagiarism that rivals some graduating seniors. No significant differences were seen in posttest scores by college.

Students scored in the 90th percentile for questions defining plagiarism, the penalties, and what is included in a citation. They had slightly more trouble and scored in the 80th percentile for questions defining paraphrasing, determining when to use direct quotes, and identifying what type of information needs to be cited. When asked to describe acceptable paraphrasing, students identified it as merely rewriting the original passage rather than synthesizing the original passage and writing it in their own words. Students did not see using direct quotes or paraphrases as a means to validate and support their ideas. Rather, they viewed using the work of others as a means to communicate their ideas better than they think they can. This may indicate that students do not yet see themselves as scholars and critical thinkers. Additionally, students did not believe they needed to cite a talk or presentation given by a friend.

Students displayed a complete lack of ability in the practical application of paraphrasing. They could not read an original passage and identify what was wrong with a paraphrase. Only 29 percent of the students in this study were able to identify what was wrong with a plagiarized paraphrase. They scored, on average, 33.5 percent when the problem was that a portion of the paraphrase was a direct quote and needed to be in quotation marks, and they scored only 24.4 percent when the paraphrased passage followed the original source too closely.

\begin{tabular}{|c|c|}
\hline \multicolumn{2}{|c|}{$\begin{array}{c}\text { TABLE } 4 \\
\text { Comparison of Pre- and Posttest } \\
\text { Scores }(\mathrm{N}=\mathbf{2 , 8 2 9}) \\
\end{array}$} \\
\hline Mean Pretest Score & 85.6 percent \\
\hline $\begin{array}{l}\text { Mean Posttest } \\
\text { Score }\end{array}$ & 91.6 percent \\
\hline $\begin{array}{l}\text { Difference from } \\
\text { Pretest to Posttest }\end{array}$ & +6 percent \\
\hline
\end{tabular}

The posttest included three openended questions that asked students to read an original passage of no more than three sentences and write a paraphrase. Most students did provide a citation for their paraphrase; however, in general, the paraphrases followed the original passage too closely. Students often used exact language from the original passage without using quotation marks, rearranged the sentence structure of the original passage, or simply replaced certain words to make it their own. Students frequently overused direct quotes in places where they seemingly had little impact, perhaps as a tactic to avoid plagiarism. Furthermore, many students failed to digest and paraphrase the entire original passage, leaving out meaning that was critical to the original author's intent.

Comparison of pre- and posttest results assessed students' general understanding of plagiarism and citing sources, but not their ability to recognize plagiarism in paraphrases. The pretest did not include questions that assessed students' abilities to recognize plagiarism in paraphrases. Thus, posttest questions requiring students to identify what was wrong with a paraphrase were removed from this portion of the analysis. The average overall pretest score was 85.6 percent. The average posttest score, minus questions assessing students' ability to identify paraphrasing flaws, was 91.6 percent, showing an improvement in students' basic understanding of plagiarism. First-time freshmen scored 90.9 percent, upper-division scored 93 percent, lower-division scored 
91.9 percent, and students not registered as part of a course scored 90.7 percent. Thus, on average, students' understanding of plagiarism and citing sources improved 6 percent from pre- to posttest.

\section{Discussion and Conclusion}

Results of this study make it clear that students need more instruction and practice with proper paraphrasing. They lack the ability to read an original passage and identify what is wrong with a paraphrase. Students do not grasp the concept that paraphrasing involves synthesizing the original passage and writing it in their own words. Some instructors have opted to go through the tutorial with their students during a regular class session. These instructors concentrate more time on the paraphrasing examples and use the open-ended paraphrasing quiz questions as in-class assignments. Further investigation is needed to determine the effectiveness of this method; however, the collaboration between instructors and the library in developing instructional resources for use in the classroom is noteworthy.

This tutorial focuses primarily on plagiarism, paraphrasing, and citing sources. Ethics instruction is lacking. As Rolf Norgaard states: "plagiarism becomes an opportunity to discuss broader intellectual, social, and ethical issues - issues that national information-literacy standards and guidelines themselves seek to broach." ${ }^{34}$ It is important for students to understand how plagiarism fits into the broader context of academic integrity and ethics. Real-world examples that explain intellectual property and copyright are under development and will be added to the tutorial.

The use of educational technologies may not be the solution to every instructional problem; however, Web-based information literacy tutorials can make significant contributions to student learning. When completed prior to the in-person information literacy session, librarians can use student quiz data to guide what they teach. Because Web-based tutorials are done outside regular class time and space, they lend themselves to the successful incorporation of information literacy into curricula.

While tutorials are by no means presented as stand-alone cures to the overall problem of teaching students academic integrity, they do provide a foundation on which a campus can build a solid instructional program about plagiarism. Plagiarism instruction needs to be introduced, reinforced, and integrated throughout the college experience to ensure graduation of ethical students. Web-based tutorials introduce concepts, assess student learning, provide educators with data about students' understanding of academic integrity, and give instructors an opportunity to reinforce important concepts in the classroom. A tutorial such as Plagiarism: The Crime of Intellectual Kidnapping is but one building block toward graduating students with a solid code of ethics and academic integrity.

\section{Notes}

1. "Center for Academic Integrity, "CAI Research," Center for Academic Integrity. Available online at http://www.academicintegrity.org/cai_research.asp [Accessed March 27, 2005]; Donald McCabe, "Cheating: Why Students Do It and How We Can Help Them Stop," American Educator 25, no. 4 (2001): 38-43.

2. Brian Hansen, “Combating Plagiarism," CQ Researcher 13, no. 32 (2003): 773-96.

3. Charles Gibson (Anchor), "A Primetime Investigation: Caught Cheating," Primetime Thursday (Television Broadcast), ABC Television Network, April 29, 2004.

4. Pamela A. Jackson et al., Plagiarism: The Crime of Intellectual Kidnapping, (San José: San José State University Library, 2003). Available online at http://tutorials.sjlibrary.org/plagiarism/index. htm.

5. Joan K. Lippincott, "Net Generation Students and Libraries," in Educating the Net Generation, eds. Diana G. Oblinger and James L. Oblinger (Boulder, Colo.: Educause, 2005). Available online at 
http://www.educause.edu/educatingthenetgen/. [Accessed April 1, 2005]; Kate Manuel, “Teaching Information Literacy to Generation Y," Journal of Library Administration 36, no. 1/2 (2002): 195-217.

6. James Nichols, Barbara Scaffer, and Karen Shockey, "Changing the Face of Instruction: Is Online or In-class More Effective?," College \& Research Libraries 64, no. 5 (2003): 378-88; William A. Orme, "A Study of the Residual Impact of the Texas Information Literacy Tutorial on the Information-Seeking Ability of First Year College Students," College \& Research Libraries 65, no. 3 (2004): 205-15.

7. Zorana Ercegovac and John V. Richardson Jr., "Academic Dishonesty, Plagiarism Included, in the Digital Age: A Literature Review," College \& Research Libraries 64, no. 4 (2004): 306-9.

8. Margaret Burke, "Deterring Plagiarism: A New Role for Librarians," Library Philosophy and Practice 6, no. 2 (2004): 1-9; John Gresham, "Cyber-Plagiarism: Technological and Cultural Background and Suggested Responses," Catholic Library World 73, no. 1 (2002): 16-19.

9. D. Scott Brandt, "Copyright's (Not So) Little Cousin, Plagiarism," Computers in Libraries 22, no. 5 (2002): 39-41.

10. Nicole J. Auer and Ellen M. Krupar, "Mouse Click Plagiarism: The Role of Technology in Plagiarism and the Librarian's Role in Combating It," Library Trends 49, no. 3 (2001): 424.

11. Ibid., 425.

12. Janet McNeil Hurlbert, Cathleen R. Savidge, and Georgia R. Laudenslager, "Process-Based Assignments: How Promoting Information Literacy Prevents Plagiarism," College E Undergraduate Libraries 10, no. 1 (2003): 39-51.

13. Lynn D. Lampert, "Integrating Discipline-Based Anti-Plagiarism Instruction into the Information Literacy Curriculum," Reference Services Review 32, no. 4 (2004): 347-55.

14. Brandt, "Copyright's (Not So) Little Cousin, Plagiarism," 40.

15. Stephen Wilhoit, "Helping Students Avoid Plagiarism," College Teaching 42, no. 4 (1994): 161-64.

16. Robert A. Harris, The Plagiarism Handbook: Strategies for Preventing, Detecting, and Dealing With Plagiarism (Los Angeles: Pyrczak Publishing, 2001); Gresham, "Cyber-Plagiarism," 16-19; Susannah Feldman, Virginia Anderson, and Luz Mangurian, "Teaching Effective Science Writing: Refining Students' Writing Skills Within the Towson Transition Course," Journal of College Science Teaching 30, no. 7 (2001): 446-49.

17. Donald McCabe and Linda Klebe Trevino, "What We Know About Cheating in College: Longitudinal Trends and Recent Developments," Change 28 (1996): 29-33.

18. Ruth Stubbings and Alan Brine, "Plagiarism and the Role of the Library," Library \& Information Update 2, no. 12 (2003): 42-4.

19. Miguel Roig, "Can Undergraduate Students Determine Whether Text Has Been Plagiarized?" The Psychological Record 47 (1997): 117.

20. Miguel Roig, "When College Students' Attempt at Paraphrasing Become Instances of Potential Plagiarism," Psychological Record 84, no. 3 (1999): 973-82.

21. Julio G. Soto, Sulekha Anand, and Elizabeth McGee, "Plagiarism Avoidance: An Empirical Study Examining Teaching Strategies," Journal of College Science Teaching 33, no. 7 (2004): 6.

22. Peter Ashworth, Philip Bannister, and Pauline Thorne, "Guilty in Whose Eyes? University Students' Perceptions of Cheating and Plagiarism in Academic Work and Assessment," Studies in Higher Education 22, no. 2 (1997): 187-203.

23. Verity J. Brown and Mark E. Howell, “The Efficacy of Policy Statements on Plagiarism: Do They Change Students' Views?" Research in Higher Education 42, no. 1 (2001): 103-18.

24. Stuart Hannabuss, "Contested Texts: Issues of Plagiarism," Library Management 22, no. 6/7 (2001): 311-18; Rebecca Moore Howard, "Plagiarisms, Authorships, and the Academic Death Penalty," College English 57, no. 7 (1995): 788-806. 41.

25. Donald McCabe and Linda Klebe Trevino, "Honesty and Honor Codes," Academe 88 (2002):

26. C. Brian Smith, "Fighting Cyberplagiarism," Library Journal NetConnect (2003): 22-23.

27. Pamela A. Jackson, "Plagiarism Tutorial Meeting the Challenge," Books \& Bytes 2, no. 2 (2004): 6. Available online at http://www.sjlibrary.org/about/sjsu/Spring2004.pdf. [Accessed March 27, 2005 ]

28. Renoir Gaither, Plagiarism Detection Services, University of Michigan, Shapiro Undergraduate Library. Available online at http://www.lib.umich.edu/acadintegrity/instructors/violations/detection.htm. [Accessed October 10, 2005].

29. Pamela A. Jackson, "The Scientific Research Process," in Empowering Students II: Teaching Information Literacy Concepts with Hands-on and Minds-on Activities, eds. Carol Anne Germain and Deborah Bernnard, 65-68 (Pittsburgh, Penn.: Library Instruction Publications, 2004).

30. Pamela A. Jackson et al., Plagiarism: The Crime of Intellectual Kidnapping. Toronto, Ontario, Canada.

31. Karen E. Hamilton, The Plagiarism Self-Assessment (George Brown College, city?). Available 
online at http://www.gbrownc.on.ca/saffairs/stusucc/plagiarism/selfassessment.html. [Accessed March 27, 2005].

32. The Regents of the University of California, NetTrail Open Publication License Agreement, (University of California at Santa Cruz). Available online at http://nettrail.ucsc.edu/admin/about. html [Accessed 27 March 2005]; University of Texas System Digital Library, TILT Open Publication License, (University of Texas at Austin). Available online at http://tilt.lib.utsystem.edu/yourtilt/ agreement.html [Accessed March 27, 2005].

33. Colleen McKenna and Joanna Bull, "Designing Effective Objective Test Questions: An Introductory Workshop," (workshop, Computer Assisted Assessment Centre, Loughborough University, Leicestershire, UK, June 17, 1999). Available online at http://caacentre.lboro.ac.uk/dldocs/otghdout.pdf. [Accessed March 27, 2005]. Thomas M. Haladyna, Developing and Validating Multiple-Choice Test Items, 3rd ed. (Mahwah, N.J.: Lawrence Erlbaum Associates, 2004).

34. Rolf Norgaard, "Writing Information Literacy in the Classroom: Pedagogical Enactments and Implications," Reference \& User Services Quarterly 43, no. 3 (2004): 223.

\section{0,000 Publishing Sources. 3.2 Million Book Titles. We're Connected. Are You?}

IT'S EASY TO BE CONNECTED WHEN YOU'RE AN EMERY-PRATT CUSTOMER.

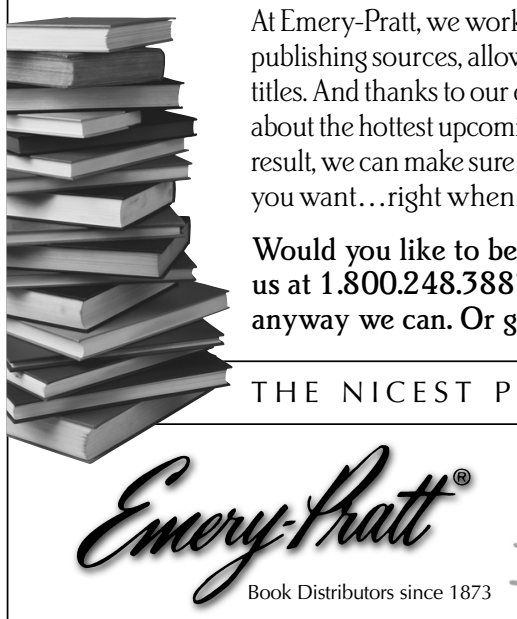

At Emery-Pratt, we work extra hard to be closely connected to more than 70,000 publishing sources, allowing you to have access to millions of new book tes. And thanks to our close relationship with these sources, we learn (heoks long before they released. As a result, we can make sure you and your customer get all the books you want... right when you want them.

Would you like to be connected? It's easy. Just call us at 1.800.248.3887. We'd love to help you anyway we can. Or go online at emery-pratt.com

1966 West M-21, Owosso, Ml 48867-1397 | Phone (toll-free) 1.800.248.3887 Fax (toll-free) 1.800.523.6379 | E-mail: mail@emery-pratt.com 